\title{
Do Life-sustaining Treatment Orders Match Patient and Surrogate Preferences? The Role of POLST
}

\author{
Susan E. Hickman, $P h D^{1,2,3,4}$, Alexia M. Torke, MD 2,3,4, Greg A. Sachs, $M D^{2,3,4}$, \\ Rebecca L. Sudore, MD', Qing Tang, MS ${ }^{6,7}$, Giorgos Bakoyannis, PhD ${ }^{6,7}$, \\ Nicholette Heim Smith, BSN ${ }^{7}$, Anne L. Myers, MPH' , and Bernard J. Hammes, PhD ${ }^{8}$
}

\begin{abstract}
'Indiana University School of Nursing, Department of Community \& Health Systems, 1101 West 10th Street, IN Indianapolis, USA; ${ }^{2}$ Research in Palliative and End-of-Life Communication \& Training (RESPECD) Signature Center, Indiana University Purdue University Indianapolis, Indianapolis, IN, USA; ${ }^{3}$ Indiana University School of Medicine, Division of General Internal Medicine \& Geriatrics, 1101 West 10th Street, IN Indianapolis, USA; ${ }^{4}$ Indiana University Center for Aging Research, Regenstrief Institute, Inc., Indianapolis, IN, USA; ${ }^{5}$ Division of Geriatrics, University of California San Francisco, School of Medicine, San Francisco, CA, USA; ${ }^{6}$ Department of Biostatistics, Indiana University School of Medicine, Indianapolis, IN, USA; ${ }^{7}$ Fairbanks School of Public Health, Indiana University, Indianapolis, IN, USA; ${ }^{2}$ Respecting Choices, A Division of C-TAC Innovations, La Crosse, WI, USA.
\end{abstract}

BACKGROUND: It is essential to high-quality medical care that life-sustaining treatment orders match the current, values-based preferences of patients or their surrogate decision-makers. It is unknown whether concordance between orders and current preferences is higher when a POLST form is used compared to standard documentation practices.

OBJECTIVE: To assess concordance between existing orders and current preferences for nursing facility residents with and without POLST forms.

DESIGN: Chart review and interviews.

SETTING: Forty Indiana nursing facilities (29 where POLST is used and 11 where POLST is not in use).

PARTICIPANTS: One hundred sixty-one residents able to provide consent and 197 surrogate decision-makers of incapacitated residents with and without POLST forms.

MAIN MEASUREMENTS: Concordance was measured by comparing life-sustaining treatment orders in the medical record (e.g., orders about resuscitation, intubation, and hospitalization) with current preferences. Concordance was analyzed using population-averaged binary logistic regression. Inverse probability weighting techniques were used to account for non-response. We hypothesized that concordance would be higher in residents with POLST ( $n=$ $275)$ in comparison to residents without POLST $(n=83)$.

KEY RESULTS: Concordance was higher for residents with POLST than without POLST (59.3\% versus $34.9 \%$ ). In a model adjusted for resident, surrogate, and facility characteristics, the odds were 3.05 times higher that residents with POLST had orders for life-sustaining treatment match current preferences in comparison to residents without POLST (OR 3.05 95\% CI 1.67-5.58, $p<$ $0.001)$. No other variables were significantly associated with concordance.

CONCLUSIONS: Nursing facility residents with POLST are significantly more likely than residents without

Electronic supplementary material The online version of this article (https://doi.org/10.1007/s11606-020-06292-1) contains supplementary material, which is available to authorized users.

Received January 21, 2020

Accepted October 5, 2020

Published online October 27, 2020
POLST to have concordance between orders in their medical records and current preferences for life-sustaining treatments, increasing the likelihood that their treatment preferences will be known and honored. However, findings indicate further systems change and clinical training are needed to improve POLST concordance.

KEY WORDS: nursing home; advance care planning; palliative care.

J Gen Intern Med 36(2):413-21

DOI: $10.1007 / \mathrm{s} 11606-020-06292-1$

(C) Society of General Internal Medicine 2020

\section{INTRODUCTION}

Mismatches between patient preferences and medical care are a threat to health care quality, especially for high stakes interventions such as cardiopulmonary resuscitation or mechanical ventilation. ${ }^{1}$ Advance care planning (ACP) is the process of eliciting and documenting these preferences following exploration of values, goals, and treatment preferences for future medical care. The overarching goal of ACP is to ensure that "people receive medical care that is consistent with their values, goals and preferences during serious and chronic illness." 2 ACP is an integral part of achieving goal-concordant care. ${ }^{3}$ Important outcomes of ACP include ensuring that documented preferences are available when needed to guide treatment decisions, and confirming that the medical record contains physician orders about preferences when appropriate. ${ }^{4}$

The POLST program was designed to document preferences for life-sustaining treatments as standardized medical orders for those at risk for a life-threatening clinical event due to a serious, life-limiting medical condition. POLST is currently used in a majority of states for thousands of patients. In Oregon alone, where POLST was originally developed, 55,030 POLST forms were submitted to a statewide electronic registry in $2019 .^{5}$ Studies in hospice, ${ }^{6}$ community programs, ${ }^{7}$ emergency response, ${ }^{8,9}$ and nursing facilities ${ }^{10-12}$ demonstrate that POLST orders are associated with treatments provided and location of death. ${ }^{13,14}$ For example, nursing facility patients with POLST 
comfort measures orders are $67 \%$ less likely to be transferred to the hospital than patients with POLST full treatment orders. Patients with POLST comfort measures orders are 59-71\% less likely to receive life-sustaining medical interventions than patients with code status orders alone and no POLST. ${ }^{10}$

Given the effectiveness of POLST at altering treatment outcomes, ${ }^{15}$ it is especially important that POLST orders match current preferences. However, information about POLST concordance is limited to a few descriptive studies with small sample sizes and no comparison groups. ${ }^{9,16-18}$ It is unknown how POLST compares with traditional practices. ${ }^{19}$

The goal of this study was to measure concordance between life-sustaining treatment orders in the medical record and current treatment preferences for nursing facility residents with and without POLST. We hypothesized, a priori, that concordance would be higher in residents with POLST in comparison to residents without POLST.

\section{METHODS}

\section{Setting}

The study was conducted between August 2016 and January 2019 in Indiana nursing facilities. The Indiana Physician Orders for Scope of Treatment (POST), Indiana's version of POLST, was introduced in 2013 and endorsed as meeting all national program and form quality standards in $2017 .{ }^{20}$ (For simplicity, the acronym POLST will always be used in this manuscript.) The study was approved by the Indiana University Institutional Review Board.

\section{Nursing Facility Identification}

Nursing facilities were eligible for inclusion if they had more than 70 skilled beds. Facilities were sorted into POLST using and non-POLST using groups using responses to a previously conducted statewide survey. ${ }^{21}$ Nursing facilities were then stratified by the proportion of racial and ethnic minority populations, location using data from the Centers for Medicare and Medicaid Services (urban versus rural). A random sample of POLST using and non-POLST facilities was identified to approach, prioritizing facilities with higher proportions of racial and ethnic minority residents. It was expected that participants with and without POLST in POLST using facilities would differ by age, health status, and other potentially confounding variables, so residents without POLST forms were selected from non-POLST using facilities.

\section{Participants}

Residents and surrogates of residents without decisional capacity were eligible for inclusion if they met the following criteria: ${ }^{1}$ resident was aged 65 or older $^{2}$; resident had a minimum length of stay of 60 days or longer ${ }^{3}$; resident's chart contained orders reflecting preferences (a POLST form in POLST using facilities or code status order in non-POLST using facilities $)^{4}$; potential participant confirmed as decisionmaker who informed orders reflecting preferences ${ }^{5}$; willing and able to participate in the study ${ }^{6}$; fluent in English; and $^{7}$ a score of $\geq 21$ on the Telephone Interview for Cognitive Status (TICS). ${ }^{22}$ Residents were also required to pass an informed consent verification assessment. ${ }^{23}$

\section{Procedures}

Research assistants were certified in the Respecting Choices Advanced Steps (RCAS) POLST facilitation model $^{24}$ and received additional training including observed role-plays using standardized patients. Permission was obtained from nursing facilities to collect data onsite and medical records were reviewed to identify potentially eligible participants. Information abstracted from the medical record included resident characteristics and treatment preferences documented as orders in the medical record, either on the POLST form or as a general medical order. In POLST using facilities, the decision-maker was identified based on who signed the POLST form (resident or surrogate). In non-POLST using facilities, the identity of the decision-maker was determined through consultation with the nursing facility contact regarding whether the resident was able to make his or her own health care decisions. If the resident was not able to make decisions, the staff contact confirmed whether the decision-maker documented in the medical record was correct. Participants were then randomly selected for potential participation with the goal of enrolling up to 10 residents and 10 surrogates in each facility. Non-white residents were oversampled using a pre-determined sampling plan in order to help ensure that the percent of non-whites was similar to national demographic characteristics. ${ }^{25}$ Nursing facility staff reviewed the list of potentially eligible participants to identify residents and surrogates inappropriate for inclusion due to changes in health status or psychosocial concerns.

Residents were introduced to the research assistant by a member of the nursing facility staff and invited to participate in the study. Residents were further screened with an informed consent verification process. ${ }^{23}$ Surrogates were sent a packet by mail that contained a letter of information with the option to opt out of receiving a call about study participation. Verbal consent was obtained by phone prior to the interview. All potential participants completed the TICS cognitive screening tool prior to reviewing the consent form and participation was discontinued if the score indicated more than mild cognitive impairment. Fidelity monitoring was performed throughout the study using digital recordings to ensure adherence to the RCAS model. ${ }^{26}$ 


\section{Data Collection Tools}

The primary outcome was concordance, which was determined by comparing life-sustaining treatment orders with current treatment preferences.

Life-sustaining Treatment Orders. Orders reflecting preferences for cardiopulmonary resuscitation, hospitalization, intubation, and comfort care were abstracted from the POLST form (for POLST-using residents) and the medical orders section of the chart and/or the face page (for non-POLST using residents).

Current Treatment Preferences. The RCAS interview ${ }^{26}$ was used to elicit values-based treatment preferences. The interview begins with an exploration of understanding about current medical conditions and complications, experiences with hospitalization, hopes, fears, and what makes life worth living. Standardized education is provided about the benefits and burdens of CPR, assistance with breathing, and hospitalization using scripting and handouts to support informed decision-making. Questions are encouraged and perceptions of burden, benefit, and acceptable outcomes are explored. Participants are asked to confirm the identified POLST order that best reflects treatment preferences, with further exploration to resolve inconsistencies.

Concordance. Concordance was measured by comparing current treatment preferences with the following orders ${ }^{1}$ : resuscitation code status (code status orders in chart/section A on POLST) and $^{2}$ medical inventions (hospitalization and intubation preferences in chart/section B on POLST). See Supplemental Table 1 for more information. The overall concordance rate was based on a $100 \%$ match between all orders and current preferences for resuscitation and medical interventions. If there was no order documented in the record, it was counted as concordant if the participant identified a preference for full intervention since full intervention is the default level of care provided in the absence of orders specifying limitations.

Participant Characteristics. Resident age, race, ethnicity, gender, and diagnoses were obtained from the Minimum Data Set (MDS) 3.0. Surrogate age, race, gender, and surrogate and resident education level were obtained during the interview.

Functional Status. Resident functional status was assessed using the Activities of Daily Living Scale derived from MDS data. $^{27}$

Cognitive Functioning. Surrogates and residents were administered the TICS during screening. Additionally, MDS data was used to calculate the Cognitive Functioning Scale for all residents. ${ }^{28}$
Health Literacy. Three previously validated self-report questions were used to assess health literacy. The items are rated on a 5-point Likert scale with a higher overall score indicating lower health literacy. ${ }^{29-31}$

Health Status. Participants were asked if the resident's health had changed over the past year. Response options were "much better," "somewhat better," "about the same," "somewhat worse," or "much worse". 32

Conversation Recall. Participants were asked if they remembered talking with anyone about preferences for lifesustaining treatment.

\section{Statistical Analysis}

Data analysis was performed with SAS version 9.4 (SAS Institute, Inc., Cary, NC) and RStudio Version 1.1.414 (RStudio, Inc.). Descriptive statistics were compiled with absolute frequencies and proportions for categorical variables, and median and interquartile range (IQR) for continuous variables. The Pearson chi-square test or Fisher's exact test was used for the comparison of the categorical characteristics between the POLST using and non-POLST using group. The Wilcoxon rank-sum test was used for the comparison of the continuous characteristics between the POLST using and non-POLST using groups. To account for potential selection bias for randomly selected facilities that refused to participate in the study, we used inverse probability weighting. ${ }^{33}$ To do this, we fitted a logistic model for the probability of response, defined as the agreement of a randomly selected facility to participate in the study, with covariates of POLST use (rural/ urban status, profit status, percent of minority, staff training in ACP, CMS Five-Star rating for staffing and skilled bed capacity). ${ }^{34}$ In this analysis, we imposed the missing at random assumption that there were no other variables associated with the probability of non-response. Then, we performed a weighted logistic regression for concordance, where the weights were estimated based on the fitted response probability model.

To account for the potential association between residents in the same facility and also incorporate the variability in the estimated weights, we used a non-parametric cluster bootstrap for standard error estimation. ${ }^{35}$ This analysis provided population-averaged estimates of the parameters of interest as well as standard error estimates that correctly reflect all the sources of variability. The covariates considered in the model for the probability of concordance included POLST use, residents' age, ADLs/functional status, cognitive functioning, Alzheimer's and/or other dementia, health literacy, identity of decision-maker (resident or surrogate), race/ minority status, conversation recall, decision-maker level of education, and change in resident's health status over the past year. 
Table 1 Comparison of Participating POLST Using and Non-POLST Using Nursing Facilities

\begin{tabular}{|c|c|c|c|c|}
\hline & $\begin{array}{l}\text { POLST using } \\
(n=29)\end{array}$ & $\begin{array}{l}\text { Non-POLST using } \\
(n=11)\end{array}$ & $\begin{array}{l}\text { Total } \\
(n=40)\end{array}$ & $p$ value \\
\hline \multicolumn{5}{|l|}{ Rural/urban, no. (\%) } \\
\hline Rural, no. (\%) & $7(24.1 \%)$ & $5(45.5 \%)$ & $12(30.0 \%)$ & \multirow[t]{2}{*}{0.25} \\
\hline Urban, no. $(\%)$ & $22(75.9 \%)$ & $6(54.5 \%)$ & $28(70.0 \%)$ & \\
\hline \multicolumn{5}{|l|}{ Profit status, no. (\%) } \\
\hline For profit & $9(31.0 \%)$ & $4(36.4 \%)$ & $13(32.5 \%)$ & \multirow[t]{4}{*}{0.81} \\
\hline Non-profit/other & $9(31.0 \%)$ & $2(18.2 \%)$ & $11(27.5 \%)$ & \\
\hline Government & $10(34.5 \%)$ & $5(45.5 \%)$ & $15(37.5 \%)$ & \\
\hline Not listed & $1(3.4 \%)$ & 0 & $1(2.5 \%)$ & \\
\hline \multicolumn{5}{|l|}{ Star rating*_overall, no. $(\%)$} \\
\hline 1 & $3(10.3 \%)$ & $2(18.2 \%)$ & $5(12.5 \%)$ & \multirow[t]{5}{*}{0.57} \\
\hline 2 & $1(3.4 \%)$ & $1(9.1 \%)$ & $2(5.0 \%)$ & \\
\hline 3 & $8(27.6 \%)$ & $3(27.3 \%)$ & $11(27.5 \%)$ & \\
\hline 4 & $8(27.6 \%)$ & $4(36.4 \%)$ & $12(30.0 \%)$ & \\
\hline 5 & $9(31.0 \%)$ & $1(9.1 \%)$ & $10(25.0 \%)$ & \\
\hline \multicolumn{5}{|l|}{ Star rating*_-staffing, no. $(\%)$} \\
\hline 1 & 0 & 0 & 0 & \multirow[t]{5}{*}{0.84} \\
\hline 2 & $5(17.2 \%)$ & $2(18.2 \%)$ & $7(17.5 \%)$ & \\
\hline 3 & $9(31.0 \%)$ & $4(36.4 \%)$ & $13(32.5 \%)$ & \\
\hline 4 & $11(37.9 \%)$ & $5(45.5 \%)$ & $16(40.0 \%)$ & \\
\hline 5 & $4(13.8 \%)$ & 0 & $4(10.0 \%)$ & \\
\hline Skilled bed capacity, median (IQR) & $114.0(48.0)$ & $96.0(36.0)$ & $103.5 .0(49.5)$ & 0.21 \\
\hline Percent of non-white, median (IQR) & $11.5(23.2)$ & $5.1(15.8)$ & $6.1(21.5)$ & 0.21 \\
\hline
\end{tabular}

*Star rating is a quality indicator metric reported by the Centers for Medicare \& Medicaid Services, where a higher score indicates better quality ${ }^{34}$

\section{RESULTS}

\section{Participating Facilities, Residents, and Surrogates}

Participating Facilities. Among eligible nursing facilities randomized for potential inclusion, 40/70 (57.1\%) were confirmed eligible and allowed data collection. See Figure 1 for details. There were no differences between POLST using $(n=29)$ and non-POLST using $(n=11)$ facilities in terms of rural/urban location, overall proportion of racial and ethnic minorities, total beds, or star ratings. Facility characteristics are presented in Table 1.

Participating Resident and Surrogate Decision-makers. About half $(52.3 \% ; 161 / 308)$ of eligible residents and $45.5 \%$ (197/433) of eligible surrogates consented to participate in the study. See Figure 2 for details. There were no significant differences in age, gender, schooling, cognition, or health literacy between decision-makers for residents with and without POLST. However, POLST decision-makers were less

Table 2 Comparison of Decision-Maker Characteristics for Residents with and without POLST Forms

\begin{tabular}{|c|c|c|c|c|}
\hline Decision-maker characteristic & $\begin{array}{l}\text { POLST } \\
(n=275)\end{array}$ & $\begin{array}{l}\text { Non-POLST } \\
(n=83)\end{array}$ & $\begin{array}{l}\text { Total } \\
(n=358)\end{array}$ & $p$ value \\
\hline \multicolumn{5}{|l|}{ Identity, no. (\%) } \\
\hline Resident & $123(44.7 \%)$ & $38(45.8 \%)$ & $161(45.0 \%)$ & 0.87 \\
\hline Surrogate & $152(55.3 \%)$ & $45(54.2 \%)$ & $197(55.0 \%)$ & \\
\hline \multicolumn{5}{|l|}{ Age, median (IQR), years } \\
\hline Resident & $78.7(14.5)$ & $74.1(16.7)$ & $78.1(15.1)$ & 0.11 \\
\hline Surrogate & $62.5(13.0)$ & $64.0(11.0)$ & $63.0(13.0)$ & 0.19 \\
\hline Gender, no. (\% female) & $192(69.8 \%)$ & $62(74.7 \%)$ & $254(70.9 \%)$ & 0.39 \\
\hline Race, no. (\% non-white) & $38(13.8 \%)$ & $10(12.0 \%)$ & $48(13.4 \%)$ & 0.68 \\
\hline \multicolumn{5}{|l|}{ Level of education, no. (\%) } \\
\hline Some school & $97(35.3 \%)$ & $39(47.0 \%)$ & $136(38.0 \%)$ & 0.14 \\
\hline Some college & $85(30.9 \%)$ & $19(22.9 \%)$ & $104(29.1 \%)$ & \\
\hline College and above & $93(33.8 \%)$ & $25(30.1 \%)$ & $118(33.0 \%)$ & \\
\hline TICS score*, median (IQR) & $34.0(7.0)$ & $34.0(5.0)$ & $34.0(6.0)$ & 0.88 \\
\hline Health literacy ${ }^{\dagger}$, median (IQR) & $1.0(1.3)$ & $1.3(1.0)$ & $1.0(1.0)$ & 0.31 \\
\hline Remembered talking with someone about the order for life-sustaining treatment, no. (\%) & $114(41.5 \%)$ & $58(69.9 \%)$ & $172(48.0 \%)$ & $<0.0001$ \\
\hline
\end{tabular}

Participating decision-makers included nursing facility residents with the capacity to make their own medical decisions and the surrogates of nursing facility residents without decisional capacity

*TICS ${ }^{T M}$ (Telephone Interview for Cognitive Status) score is a measure of cognition, where scores $<20$ indicate moderate to severe impairment, $21-25$ indicates mild impairment, 26-32 indicates ambiguous cognitive status, and 33-41 indicates no impairment ${ }^{22}$

†Health literacy score ranges from 0 to 4, where higher scores indicate lower health literacy ${ }^{30}$ 
Table 3 Comparison of Nursing Facility Residents with and without POLST Forms

\begin{tabular}{|c|c|c|c|c|}
\hline Characteristic & $\begin{array}{l}\text { POLST } \\
(n=275)\end{array}$ & $\begin{array}{l}\text { Non-POLST } \\
(n=83)\end{array}$ & $\begin{array}{l}\text { Total } \\
(n=358)\end{array}$ & $p$ value \\
\hline Age, median (IQR), years & $83.2(14.1)$ & $82.0(18.7)$ & $82.8(15.1)$ & 0.24 \\
\hline Race, no. (\% non-white) & $40(14.5 \%)$ & $11(13.3 \%)$ & $51(14.2 \%)$ & 0.77 \\
\hline Ethnicity, no. (\% Hispanic) & $4(1.5 \%)$ & 0 & $4(1.1 \%)$ & 0.27 \\
\hline \multicolumn{5}{|l|}{ Health now compared to one year ago, no. (\%) } \\
\hline Much better & $23(8.4 \%)$ & $8(9.6 \%)$ & $31(8.7 \%)$ & 0.83 \\
\hline Somewhat better & $34(12.4 \%)$ & $8(9.6 \%)$ & $42(11.7 \%)$ & \\
\hline About the same & $59(21.5 \%)$ & $22(26.5 \%)$ & $81(22.6 \%)$ & \\
\hline Somewhat worse & $124(45.1 \%)$ & $34(41.0 \%)$ & $158(44.1 \%)$ & \\
\hline Much worse & $35(12.7 \%)$ & $11(13.3 \%)$ & $46(12.8 \%)$ & \\
\hline Cognitive Function Scale score, median (IQR)* & $2.0(2.0)$ & $1.0(2.0)$ & $2.0(2.0)$ & 0.20 \\
\hline Activities of daily living, median (IQR) ${ }^{\dagger}$ & $18.0(7.0)$ & $16.0(10.0)$ & $17.0(8.0)$ & 0.47 \\
\hline Prognosis $<6$ months, no. (\% yes) & $7(2.5 \%)$ & $3(3.6 \%)$ & $10(2.8 \%)$ & 0.16 \\
\hline Hospice, no. (\% yes) & $8(2.9 \%)$ & $2(2.4 \%)$ & $10(2.8 \%)$ & 0.81 \\
\hline \multicolumn{5}{|l|}{ Diagnosis } \\
\hline Cancer & $5(1.8 \%)$ & 0 & $5(1.4 \%)$ & 0.22 \\
\hline Chronic obstructive pulmonary disease & $82(29.8 \%)$ & $29(34.9 \%)$ & $111(31.0 \%)$ & 0.38 \\
\hline Alzheimer's and/or other dementia & $152(55.3 \%)$ & $32(38.6 \%)$ & $184(51.4 \%)$ & 0.0076 \\
\hline Depression & $155(56.4 \%)$ & $42(50.6 \%)$ & $197(55.0 \%)$ & 0.36 \\
\hline Diabetes & $89(32.4 \%)$ & $31(37.3 \%)$ & $120(33.5 \%)$ & 0.40 \\
\hline Heart failure & $71(25.8 \%)$ & $26(31.3 \%)$ & $97(27.1 \%)$ & 0.32 \\
\hline Hypertension & $209(76.0 \%)$ & $56(67.5 \%)$ & $265(74.0 \%)$ & 0.12 \\
\hline Stroke & $18(6.5 \%)$ & $5(6.0 \%)$ & $23(6.4 \%)$ & 0.87 \\
\hline
\end{tabular}

* Cognitive function score scores range from 0 (cognition intact) to 6 (very severe impairment) ${ }^{28}$

†Overall scores range from 0 (independent) to 28 (total dependence) ${ }^{27}$

likely to remember talking with someone about life-sustaining treatment preferences than decision-makers without POLST $(p<0.0001$; Table 2).

Resident Characteristics. Residents with and without POLST were similar in terms of age, gender, race and ethnicity, and cognition. Residents with POLST forms were more likely to have a documented diagnosis of Alzheimer's disease and/or non-Alzheimer's dementia than residents without POLST $(p=0.008)$. See Table 3.

\section{Concordance in Residents with and without POLST}

Overall, life-sustaining treatment orders were concordant with current preferences in $53.6 \%(192 / 358)$ of cases. Orders matched current preferences in $59.3 \%(163 / 275)$ of residents with POLST compared to $34.9 \%$ (29/83) of residents without POLST. Residents with POLST forms had a 3.05 times higher odds of having preferences match orders for life-sustaining treatment in comparison to residents without POLST forms (adjusted odds ratio 3.05 95\% CI 1.67-5.58, $p<0.001$ ) after adjusting for residents' age, ADLs/functional status, cognitive functioning, health literacy, identity of decision-maker (resident or surrogate), race/minority status, conversation recall, decisionmaker level of education, and change in resident's health status over the past year. None of the other variables in the model was significantly associated with concordance (see Table 4).

\section{CONCLUSIONS}

It is essential that orders about life-sustaining treatment match patients' current preferences to help ensure goal-concordant care for patients with serious illness. In this study, nursing facility residents with POLST forms were over three times as likely to have their current treatment preferences match the orders in their medical record as residents without POLST forms. In combination with prior research, ${ }^{15}$ our results indicate POLST helps increase the likelihood that current patient preferences are known and honored. However, only $59.1 \%$ of POLST forms matched current preferences and further work is clearly needed to improve concordance.

The rate of concordance is probably higher for POLST using residents because use of a standardized form increases the likelihood that treatment preferences are documented and available. ${ }^{10}$ Several studies have noted that documentation about preferences to limit hospital transfer, tube feeding, and other interventions is often absent in nursing facilities. ${ }^{10,36-}$ ${ }^{38}$ For example, a study of residents with advanced dementia found that documentation was concordant with surrogate preferences for comfort care in just $7 \%$ of cases, because preferences for comfort care were so rarely documented. ${ }^{36}$ Unfortunately, a mismatch between preferences and documentation is common and not unique to the nursing facility setting. ${ }^{39}$ Discordance may reflect that some patients and surrogates do not have treatment preferences or are ambivalent and the lack of documentation accurately reflects that no choice was made at the time. ${ }^{40}$ Alternatively, it is possible that there were 


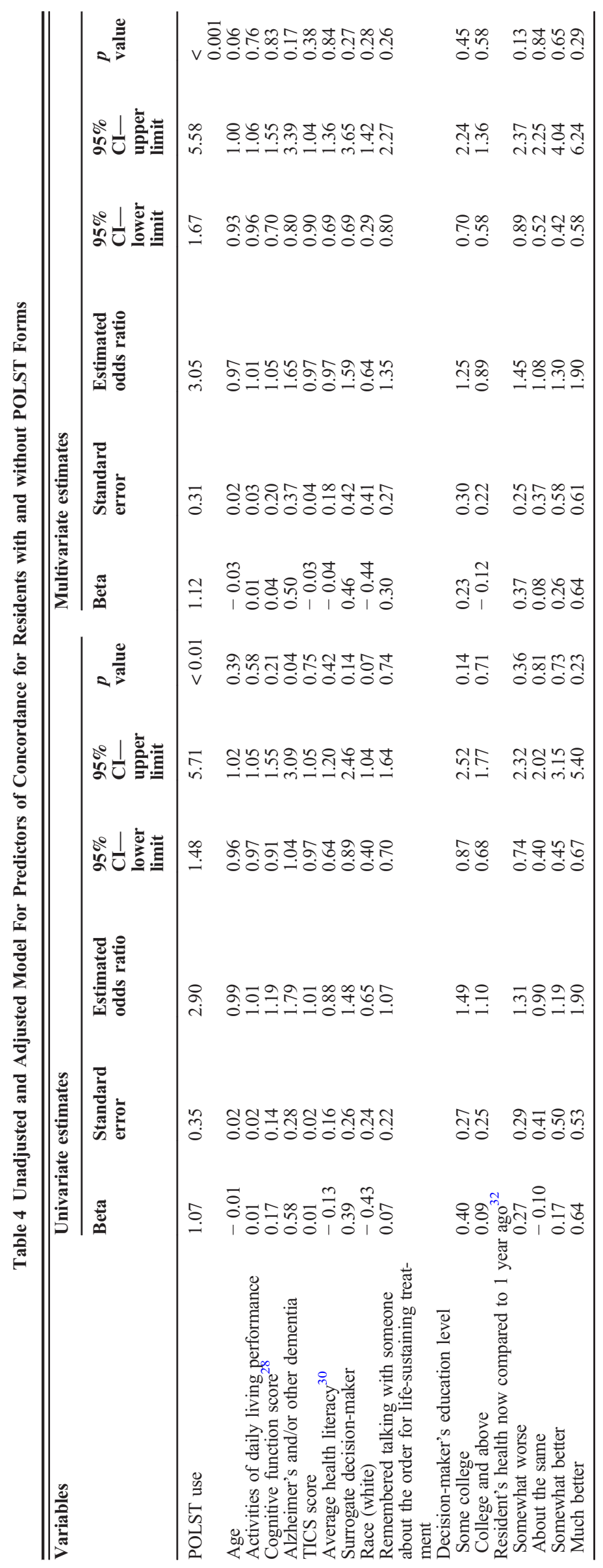


no conversations or conversations did occur but were not recorded as medical orders. ${ }^{41}$

The decision to implement POLST in a nursing facility requires a commitment to on-going education, changes to policies and procedures, and quality improvement activities $^{20}$ as well as a philosophical shift about the role of resident preferences in guiding care. Although POLST is being adopted across the country, use ofthis voluntary program is variable. ${ }^{10,14,21}$ Previously identified challenges in implementing POLST in the nursing facility setting include difficulty understanding and explaining the form and complaints about the time involved in having the POLST conversation. ${ }^{42,43}$ The findings of the present study suggest that meaningful POLST implementation should be supported as part of efforts to provide person-centered care and improve endof-life care. Policy and regulatory changes may be required to support optimal use of POLST, though every organization using POLST should engage in quality improvement activities to support best practice. ${ }^{44}$ The addition of Medicare advance care planning billing codes may result in additional funding for education and training in at least some nursing facilities. ${ }^{45}$

Like all health care interventions, POLST has both risks and potential benefits. One risk is that the presence of a POLST form implies a conversation about preferences occurred and that the orders on the form are current and well-informed. Our finding that participants with POLST were less likely to recall conversations about life-sustaining treatment preferences in comparison to participants without POLST raises questions about this assumption. There is also a risk that orders will be implemented without confirming the orders reflect current preferences. Potential benefits include increasing the likelihood of goal concordant care and the ability to identify when there is a mismatch between preferences, documentation, and treatments. The use of POLST also makes it possible to evaluate the effect of new practices designed to improve quality and increase concordance, as POLST provides a baseline on which to be able to measure and track improvement both in documentation concordance and in the consistency between preferences and treatments provided ${ }^{46}$ It is not possible to assess the effect of quality improvement efforts to increase concordance in settings that lack clear ACP documentation standards. Study findings suggest that nursing facilities that do not use POLST to document the outcomes of values-based, informed decisions are at greater risk of providing care that does not match resident preferences than nursing facilities that do.

It seems likely that a certain level of mismatch between preferences and documentation is unavoidable, but unclear what the minimally permissible level of discordance should be. There are no established standards for what is an acceptable level of concordance and this is a new area of research, but a goal of $100 \%$ concordance is likely unrealistic. However, the finding that $41 \%$ of orders on POLST and $65 \%$ of orders in
non-POLST charts were discordant with current preferences indicates a clear need for increased attention to the quality of advance care planning in nursing facilities through a system redesign that includes systems change and clinician training. ${ }^{47}$ Additional analyses are planned to evaluate variables that contribute to POLST concordance to support the development of interventions.

Limitations of the study include that it is possible prior decisions were made with others not present during data collection, including medical providers who may have made specific recommendations about lifesustaining treatment orders. ${ }^{48}$ Second, it was not always possible to assess the date of life-sustaining treatment orders in facilities where POLST was not in use, so we were unable to control for time in our analysis. Third, we compared persons in POLST using facilities with persons in non-POLST using facilities. Even though we have accounted for a number of potential confounders, it is possible that our results are confounded by other, unmeasured, patient-level and facility-level factors. This issue is ubiquitous in real-life observational studies. Fourth, the probability that a facility refused to participate may be associated with other factors that were not measured in this study and this may lead to violation of the missing at random assumption at the facility level imposed in this analysis. Therefore, the results may not necessarily generalize to nonparticipating facilities despite the use of inverse probability weighting. Finally, the low participation rates along with a potential violation of the missing at random assumption at the resident level, given the variables considered in the final multivariable model, are another possible source of bias.

The ultimate goal of ACP is to help clinicians provide care that matches the patient's current goals, values, and preferences. Study findings suggest that POLST is an important tool in achieving this goal. Residents with POLST forms were significantly more likely than residents without POLST to have their current preferences for life-sustaining treatments match orders documented in nursing facility medical records, though further work is clearly needed to improve concordance. In combination with past research suggesting POLST orders are associated with treatment outcomes, findings suggest that POLST forms significantly increase the likelihood that current patient preferences are known and available when needed to guide treatment decisions.

Acknowledgments: We thank all participating nursing facility residents and surrogate decision-makers for taking part in this study. We are deeply grateful to the nursing facilities across Indiana that collaborated with our team to make this study possible. Finally, we are grateful to research assistants Curtis Williamson, LCSW, coauthor Nicholette Heim Smith, BSN, Marcie Sherman, and Miranda Connors for their diligence, enthusiasm, and professionalism in acquiring the data. 
Corresponding Author: Susan E. Hickman, $\mathrm{PhD}$; Indiana University School of Nursing, Department of Community \& Health Systems, 1101 West 10th Street, IN 46202 Indianapolis, USA (e-mail: hickman@iu. edu).

Author Contributions Author contributions were as follows: Study concept and design (SEH, RS, GAS, AMT, BJH); acquisition of subjects and/or data (SEH, ALM, NHS); analysis and interpretation of data (SEH, RS, GAS, AMT, ALM, QT, NHS, GB, BJH); and preparation of manuscript (SEH, RS, GAS, AMT, ALM, QT, NHS, GB, BJH).

Funding Research reported in this publication was supported by the Retirement Research Foundation and the National Institute of Nursing Research of the National Institutes of Health under grant number RO1NRO15255.

\section{Compliance with Ethical Standards:}

The study was approved by the Indiana University Institutional Review Board.

Conflict of Interest: The authors report no conflicts of interest.

Disclaimer: The content is solely the responsibility of the authors and does not necessarily represent the official views of either the Retirement Research Foundation or the National Institutes of Health.

\section{REFERENCES}

1. Institute of Medicine. Dying in America, Improving Quality and Honoring Individual Preferences Near the End of Life. Washington, D.C.: The National Academies Press; 2014.

2. Sudore RL, Lum HD, You JJ, Hanson LC, Meier DE, Pantilat SZ, et al. Defining Advance Care Planning for Adults: A Consensus Definition From a Multidisciplinary Delphi Panel. J Pain Symptom Manag. 2017;53(5):821-32.e1.

3. Sanders JJ, Curtis JR, Tulsky JA. Achieving Goal-Concordant Care: A Conceptual Model and Approach to Measuring Serious Illness Communication and Its Impact. J Palliat Med 2018;21(S2):S17-s27.

4. Sudore RL, Heyland DK, Lum HD, Rietjens JAC, Korfage IJ, Ritchie CS, et al. Outcomes That Define Successful Advance Care Planning: A Delphi Panel Consensus. J Pain Symptom Manag. 2018;55(2):245-55.e8.

5. Oregon POLST Registry Annual Report Portland, OR: Oregon POLST Registry; 2019. https://orpolstregistry.files.wordpress.com/2020/09/ 2019-oregon-polst-registry-annual-report.pdf.

6. Hickman SE, Nelson CA, Moss AH, Hammes BJ, Terwilliger A, Jackson A, et al. Use of the Physician Orders for Life-Sustaining Treatment (POLST) paradigm program in the hospice setting. J Palliat Med 2009; 12(2): 133-41.

7. Lee MA, Brummel-Smith K, Meyer J, Drew N, London MR. Physician orders for life-sustaining treatment (POLST): outcomes in a PACE program. Program of All-Inclusive Care for the Elderly. J Am Geriatr Soc 2000;48(10): 1219-25.

8. Schmidt TA, Hickman SE, Tolle SW, Brooks HS. The Physician Orders for Life-Sustaining Treatment program: Oregon emergency medical technicians' practical experiences and attitudes. J Am Geriatr Soc 2004;52(9): 1430-4.

9. Schmidt TA, Olszewski EA, Zive D, Fromme EK, Tolle SW. The Oregon physician orders for life-sustaining treatment registry: a preliminary study of emergency medical services utilization. J Emerg Med 2013;44(4):796-805.

10. Hickman SE, Nelson CA, Perrin NA, Moss AH, Hammes BJ, Tolle SW. A comparison of methods to communicate treatment preferences in nursing facilities: traditional practices versus the physician orders for lifesustaining treatment program. J Am Geriatr Soc 2010;58(7):1241-8.

11. Tolle Sw, Tilden VP, Nelson CA, Dunn PM. A prospective study of the efficacy of the physician order form for life-sustaining treatment. J Am Geriatr Soc 1998;46(9):1097-102.
12. Hickman SE, Nelson CA, Moss AH, Tolle SW, Perrin NA, Hammes BJ. The consistency between treatments provided to nursing facility residents and orders on the physician orders for life-sustaining treatment form. $J$ Am Geriatr Soc 2011;59(11):2091-9.

13. Hammes BJ, Rooney BL, Gundrum JD, Hickman SE, Hager N. The POLST program: a retrospective review of the demographics of use and outcomes in one community where advance directives are prevalent. J Palliat Med 2012;15(1):77-85.

14. Fromme EK, Zive D, Schmidt TA, Cook JN, Tolle SW. Association between Physician Orders for Life-Sustaining Treatment for Scope of Treatment and in-hospital death in Oregon. J Am Geriatr Soc 2014;62(7): 1246-51.

15. Hickman SE, Keevern E, Hammes BJ. Use of the physician orders for life-sustaining treatment program in the clinical setting: a systematic review of the literature. J Am Geriatr Soc 2015;63(2):341-50.

16. Hickman SE, Hammes BJ, Torke AM, Sudore RL, Sachs GA. The Quality of Physician Orders for Life-Sustaining Treatment Decisions: A Pilot Study. J Palliat Med 2017;20(2):155-62.

17. Hickman SE, Nelson CA, Smith-Howell E, Hammes BJ. Use of the Physician Orders for Life-Sustaining Treatment program for patients being discharged from the hospital to the nursing facility. J Palliat Med 2014;17(1):43-9

18. Meyers JL, Moore C, McGrory A, Sparr J, Ahern M. Physician orders for life-sustaining treatment form: honoring end-of-life directives for nursing home residents. J Gerontol Nurs 2004;30(9):37-46.

19. Auriemma CL, Nguyen CA, Bronheim R, Kent S, Nadiger S, Pardo D, et al. Stability of end-of-life preferences: a systematic review of the evidence. JAMA Intern Med 2014;174(7):1085-92.

20. The National POLST Paradigm Washington, D.C.: National POLST Paradigm; 2019 [August 2, 2019]. Available from: https://polst.org.

21. Hickman SE, Sudore RL, Sachs GA, Torke AM, Myers AL, Tang $\mathbf{G}$, et al. Use of the Physician Orders for Scope of Treatment Program in Indiana Nursing Homes. J Am Geriatr Soc 2018;66(6):1096-100.

22. Knopman DS, Roberts RO, Geda YE, Pankratz VS, Christianson TJ, Petersen RC, et al. Validation of the telephone interview for cognitive status-modified in subjects with normal cognition, mild cognitive impairment, or dementia. Neuroepidemiology. 2010;34(1):34-42.

23. Sudore RL, Landefeld CS, Williams BA, Barnes DE, Lindquist K, Schillinger D. Use of a modified informed consent process among vulnerable patients: a descriptive study. J Gen Intern Med 2006;21(8):867-73.

24. Centers for Medicare and Medicaid Services. Nursing Home Data Compendium 2013 Edition. 2013.

25. Rietjens JAC, Korfage IJ, Dunleavy L, Preston NJ, Jabbarian LJ, Christensen CA, et al. Advance care planning - a multi-centre cluster randomised clinical trial: the research protocol of the ACTION study. BMC Cancer 2016;16(1):264.

26. Respecting Choices Person Centered Care LaCrosse, WI: Respecting Choices; [August 2, 2019]. Available from: https://respectingchoices. org/.

27. Morris JN, Fries BE, Morris SA. Scaling ADLs within the MDS. J Gerontol A Biol Sci Med Sci 1999;54(11):M546-53.

28. Thomas KS, Dosa D, Wysocki A, Mor V. The Minimum Data Set 3.0 Cognitive Function Scale. Med Care 2017;55(9):e68-e72.

29. Sarkar U, Schillinger D, Lopez A, Sudore R. Validation of self-reported health literacy questions among diverse English and Spanish-speaking populations. J Gen Intern Med 2011;26(3):265-71.

30. Chew LD, Griffin JM, Partin MR, Noorbaloochi S, Grill JP, Snyder A, et al. Validation of screening questions for limited health literacy in a large VA outpatient population. J Gen Intern Med 2008;23(5):561-6.

31. Chew LD, Bradley KA, Boyko EJ. Brief questions to identify patients with inadequate health literacy. Fam Med 2004;36(8):588-94.

32. Ware JE, Jr., Sherbourne CD. The MOS 36-item short-form health survey (SF-36). I. Conceptual framework and item selection. Med Care 1992;30(6):473-83.

33. Kim JK, Kim JJ. Nonresponse weighting adjustment using estimated response probability. Can J Stat 2007;35(4):501-14.

34. Centers for Medicare and Medicaid Services. Five-star Quality Rating System 2019. Available from: https://www.cms.gov/medicare/providerenrollment-and-certification/certificationandcomplianc/fsqrs.html.

35. Field CA, Welsh AH. Bootstrapping clustered data. J R Stat Soc: B (Stat Methodol) 2007;69(3):369-90.

36. Cohen SM, Volandes AE, Shaffer ML, Hanson LC, Habtemariam D, Mitchell SL. Concordance Between Proxy Level of Care Preference and Advance Directives Among Nursing Home Residents With Advanced 
Dementia: A Cluster Randomized Clinical Trial. J Pain Symptom Manag. 2019;57(1):37-46.e1.

37. Ernecoff NC, Zimmerman S, Mitchell SL, Song MK, Lin FC, Wessell KL, et al. Concordance between Goals of Care and Treatment Decisions for Persons with Dementia. J Palliat Med 2018;21(10): 1442-7.

38. McAuley WJ, Travis SS. Advance care planning among residents in longterm care. Am J Hosp Palliat Care 2003;20(5):353-9.

39. Heyland DK, Barwich D, Pichora D, Dodek P, Lamontagne F, You JJ, et al. Failure to engage hospitalized elderly patients and their families in advance care planning. JAMA Intern Med 2013;173(9):778-87.

40. Halpern SD, Loewenstein G, Volpp KG, Cooney E, Vranas K, Quill CM, et al. Default options in advance directives influence how patients set goals for end-of-life care. Health Affairs (Project Hope) 2013;32(2):408-17.

41. Towsley GL, Hirschman KB, Madden C. Conversations about End of Life: Perspectives of Nursing Home Residents, Family, and Staff. J Palliat Med 2015; 18(5):421-8.

42. Vo H, Pekmezaris R, Guzik H, Nouryan C, Patel C, Vij B, et al. Knowledge and attitudes of health care workers regarding MOLST (Medical Orders for Life-Sustaining Treatment) implementation in longterm care facilities. Geriatr Nurs (New York, NY) 2011;32(1):58-62.

43. Wenger NS, Citko J, O'Malley K, Diamant A, Lorenz K, Gonzalez V, et al. Implementation of Physician Orders for Life Sustaining Treatment in nursing homes in California: evaluation of a novel statewide dissemination mechanism. J Gen Intern Med 2013;28(1):51-7.

44. Quality Assurance Toolkits Washington D.C.: National POLST Paradigm; 2019 [Available from: https://polst.org/qatoolkits/?pro=1.

45. Belanger E, Loomer L, Teno JM, Mitchell SL, Adhikari D, Gozalo PL Early Utilization Patterns of the New Medicare Procedure Codes for Advance Care Planning. JAMA Intern Med 2019;179(6):829-30.

46. Unroe KT, Hickman SE, Torke AM. Care Consistency With Documented Care Preferences: Methodologic Considerations for Implementing the "Measuring What Matters" Quality Indicator. J Pain Symptom Manag 2016;52(4):453-8.

47. Hammes B, Briggs L, Silvester W, Wilson $\mathbf{K}$, Shettle $\mathbf{S}$, Maycroft $\mathbf{J}$, Sandoval J, Orders A, Stern M. Resdesigning a care planning system: How to fix the most pervasive errors in health care. Health Affairs Blog. 2015; January 2.

48. Roeland E, Cain J, Onderdonk C, Kerr K, Mitchell W, Thornberry K When open-ended questions don't work: The role of pallaitive paternalism in difficult medical decisions. J Palliat Med 2014;17(4):415-420.

Publisher's Note: Springer Nature remains neutral with regard to jurisdictional claims in published maps and institutional affiliations. 